\title{
AVALIAÇÃO DE SISTEMAS DE PROPULSÃO ELÉTRICA: MOTOR SÍNCRONO SUPERCONDUTOR DE ALTA TEMPERATURA
}

\author{
André Luís da Silva Pinheiro \\ Doutor em Engenharia Nuclear pela Universidade Federal do Rio de Janeiro (UFRJ) \\ Rio de Janeiro, RJ, Brasil \\ apinheiro99@gmail.com \\ Antônio José Dias da Silva \\ Mestre em Sistemas de Informação pela Universidade Federal do Rio de Janeiro (UFRJ) \\ Professor do Centro Universitário Augusto Motta - UNISUAM \\ Rio de Janeiro, RJ, Brasil \\ antoniojoseds@gmail.com \\ Geraldo Motta Azevedo Júnior \\ Doutor em Engenharia Elétrica pela Universidade Federal do Rio de Janeiro (COPPE/UFRJ) \\ Professor do Centro Universitário Augusto Motta - UNISUAM \\ Rio de Janeiro, RJ, Brasil \\ geraldomotta@unisuam.edu.br \\ Victor Hugo Rinaldi Fortes Henriques \\ Graduando de Engenharia Elétrica da UNISUAM, Rio de Janeiro, RJ, Brasil \\ vh.rinaldi@gmail.com
}

\section{RESUMO}

Nos dias atuais os projetistas de embarcações se deparam com o desafio de tornar os meios navais mais eficientes e que ampliem sua capacidade de transporte de cargas, pessoas ou até mesmo aumento na autonomia no caso de navios para aplicação militar. Outro desafio dos engenheiros reside na necessidade dos projetos de motores se adequarem aos padrões de emissão de poluentes estabelecidos pela Organização Marítima Internacional (IMO), que é uma agência das Nações Unidas destinada a promover a segurança marítima. Essas normas são divididas em níveis, onde o nível atual e mais desafiador é o Tier III, proibindo a emissão deliberada de gases que produzem o efeito estufa. Por esse motivo, torna-se fundamental estudar sistemas de propulsão que englobam novas tecnologias de materiais e que reduzam o consumo de combustível fóssil. O principal equipamento estudado é o motor supercondutor aplicado a propulsão naval, desenvolvido graças a evolução das ligas de material supercondutor e desenvolvimento de equipamento responsáveis pelo arrefecimento criogênico. O presente trabalho tem como proposta comparar dois tipos de propulsão, a diesel mecânica e a elétrica, verificando as suas vantagens e desvantagens, verificando a viabilidade para elaboração de um arranjo de equipamentos para propulsão que ocupe um menor volume na praça de máquinas e que tenha maior eficiência. Surge assim, a necessidade da aplicação de um motor elétrico mais eficiente do que o motor diesel. Na presente obra, pode-se concluir sobre o aspecto econômico da viabilidade do emprego da tecnologia de supercondutores no motor da propulsão, sendo possível obter um comparativo do custo global do sistema diesel mecânico que foi de $R \$ 259.270,30$ e da propulsão elétrica com motor HTS que foi de $R \$ 789.014,00$, aumento de $300 \%$ para a proposta apresentada.

Palavras-chave: Propulsão Naval, Motor Síncrono, Supercondutor HTS, Motor elétrico, Motor diesel 


\title{
EVALUATION OF ELECTRIC PROPULSION SYSTEMS: HIGH TEMPERATURE SUPERCONDUCTOR SYNCHRONOUS MOTOR
}

\begin{abstract}
Nowadays, ship designers are faced with the challenge of making naval means more efficient and expanding their capacity to transport cargo, people, or even increased autonomy in the case of ships for military application. Another challenge for engineers is the need for engine projects to adapt to the pollutant emission standards established by the International Maritime Organization (IMO), which is a United Nations agency designed to promote maritime safety. These standards are divided into tiers, where the current and most challenging tier is Tier III, prohibiting the deliberate emission of greenhouse gases. For this reason, it is essential to study propulsion systems that encompass new materials technologies and that reduce fossil fuel consumption. The main equipment studied is the superconducting motor applied to naval propulsion, developed thanks to the evolution of superconducting material alloys and the development of equipment responsible for cryogenic cooling. The present work proposes to compare two types of propulsion, mechanical and electric diesel, verifying their advantages and disadvantages, verifying the feasibility of developing an arrangement of propulsion equipment that occupies a smaller volume in the engine room and has greater efficiency. Thus, the need for the application of an electric motor more efficient than the diesel engine arises. In the present work, it is possible to conclude on the economic aspect of the viability of the use of superconductor technology in the propulsion engine, being possible to obtain a comparison of the global cost of the mechanical diesel system, which was $R \$ 259,270.30$ and of the electric propulsion with HTS engine, which was R\$ 789,014.00, an increase of $300 \%$ for the proposal presented.
\end{abstract}

Keywords: Naval Propulsion, Synchronous Motor, HTS Superconductor, Electric Motor, Diesel Engine.

\section{INTRODUÇÃO}

\subsection{Metodologia}

O método utilizado na elaboração do presente trabalho foi uma pesquisa bibliográfica feita através de trabalhos acadêmicos de instituições internacionais com vasta experiência em estudos da supercondutividade e artigos científicos. Também foram realizados comparativos de rendimento, curvas de potência, ganhos de densidade de corrente (PINA, 2010), tabulando os dados obtidos através dos testes laboratoriais de motores síncronos com supercondutores na armadura e na excitação. Ao longo do trabalho será desenvolvido um protótipo de um casco de uma embarcação de pequeno porte na ferramenta SolidWorks. A curva de potência e seleção do motor será extraída do software NavCad, a partir desses dados serão comparados os resultados dos dois arranjos da propulsão: propulsão diesel convencional e propulsão elétrica com motor síncrono supercondutor. 


\subsection{Revisão Bibliográfica}

\subsubsection{Sistemas Propulsivos}

Um sistema de propulsão naval é qualquer meio de transformação de energia proveniente de um combustível em outra forma de energia, empregada para o deslocamento da embarcação (CORDEIRO, 2010). Integra um conjunto de meios, equipamentos e acessórios, formando a máquina propulsora.

O mar, há séculos se mostra fundamental para a economia mundial, sendo responsável pelo transporte de pessoas, pesca e distribuição de mercadoria de toda variedade. O surgimento da vela permitiu ao ser humano se afastar cada vez mais da costa conseguindo realizar travessias mais longas, os primeiros povos a fazerem uso desse tipo de propulsão foram os egípcios, gregos e romanos, na Figura 1 pode ser visto um navio a vela. Logo em seguida surgiu a solução da propulsão híbrida, uma mistura da vela com o motor a vapor, estes aumentaram a velocidade dos navios. Mas, em contrapartida exigiam quantidades enormes de carvão e reduziam o espaço a bordo. 0 motor por sua vez era responsável pelo acionamento em uma roda lateral, que era extremamente robusta e por isso, atrapalhava a manobra com as velas por parte da tripulação. No século de XIX com o advento do motor diesel, o rendimento da propulsão se elevou, bem como o consumo de combustível seguiu o mesmo caminho, pois um menor volume de diesel era necessário quando comparado a quantidade de carvão exigida nos porões. Os navios voltaram a ganhar espaço e capacidade de transporte de carga (TELLES, 2001).

Figura 1 - Embarcação a vela

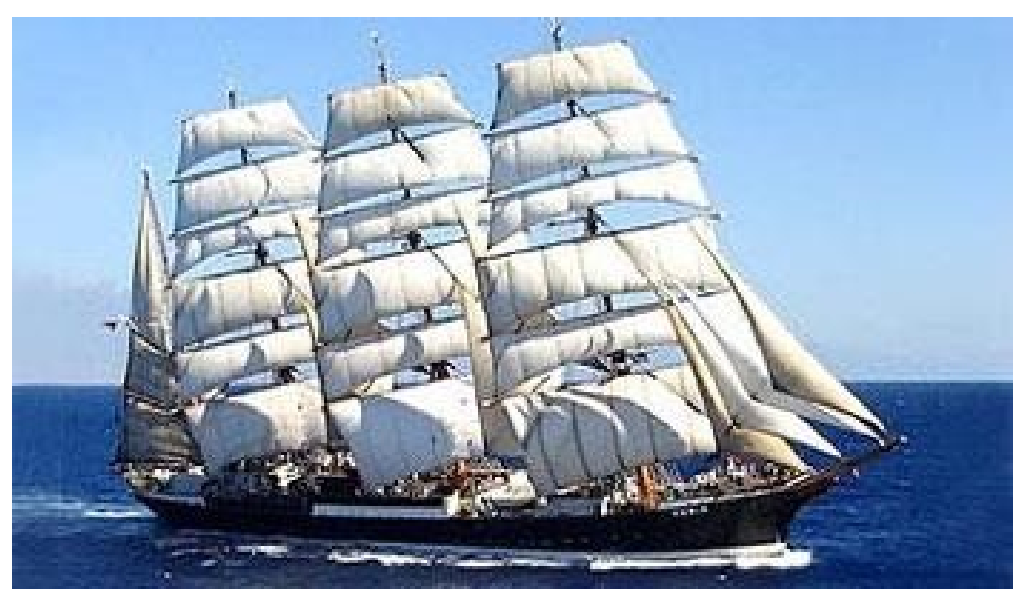

Fonte: (https://acervo.popa.com.br, acessado em 16/06/2018)

\subsubsection{Propulsão Mecânica}


Nesse sistema o grande diferencial é a empregabilidade dos Motores de Combustão Interna $(\mathrm{MCl})$, estes convertem energia química provenientes dos combustíveis fósseis em energia mecânica na ponta do eixo para movimentação dos propulsores. Durante a combustão os gases se expandem dentro dos cilindros, atuando direto nos êmbolos das máquinas. Esses motores operam em sua grande maioria com rotação de 200 a 600 rpm (AZEVEDO, 2015). A Figura 2 mostra um exemplo do acionamento Diesel-Mecânico

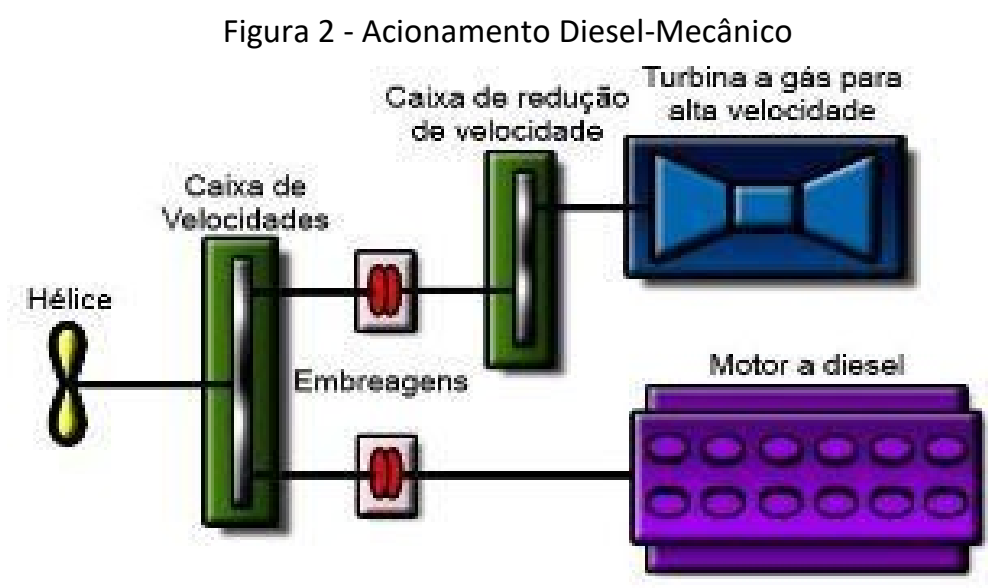

Fonte: (commons.wikimedia.org, acessado em 08/05/2018)

\subsubsection{Propulsão Elétrica}

Nesta configuração o grupo de geradores diesel é responsável pela geração da energia para acionamento dos motores elétricos. Este conjunto apresenta diversas vantagens em relação aos sistemas descritos anteriormente e possui uma série de especificidades operativas. Em navios as condições de operação são as mais diversas possíveis, sendo necessária uma alternância na potência demandada por longos períodos. Com o desenvolvimento dos submarinos pela indústria naval militar, fez-se necessário que o consumo de oxigênio a bordo fosse diminuído. Para que essa redução de oxigênio fosse conseguida, cresceu a utilização de motores de corrente contínua (AZEVEDO, 2015), que por sua vez eram alimentados por grandes grupos de baterias. Esses grupos devem ser recarregados constantemente, para isso um motor de combustão interna (MCl) é acoplado a um gerador, logo em seguida a energia gerada é retificada para recarregar as baterias. Atualmente métodos modernos para configuração de plantas elétricas vêm sendo aprimorados.

Navios transatlânticos, que requerem estabilidade e alta capacidade de manobra, nos dias de hoje já contemplam a propulsão diesel-elétrica (REIS, 2015) em seus projetos, conforme ilustradas nas Figura 3e Figura 4. A propulsão elétrica é geralmente usada em meios que requisitam alto grau de manobrabilidade e sistema DP (Dynamic Positioning), também chamados de Posicionamento 
Dinâmico. Diversos equipamentos constituem a planta de propulsão elétrica, tais como: geradores, motores elétricos, conversores de frequência, painéis elétricos, cabos elétricos, entre outros.

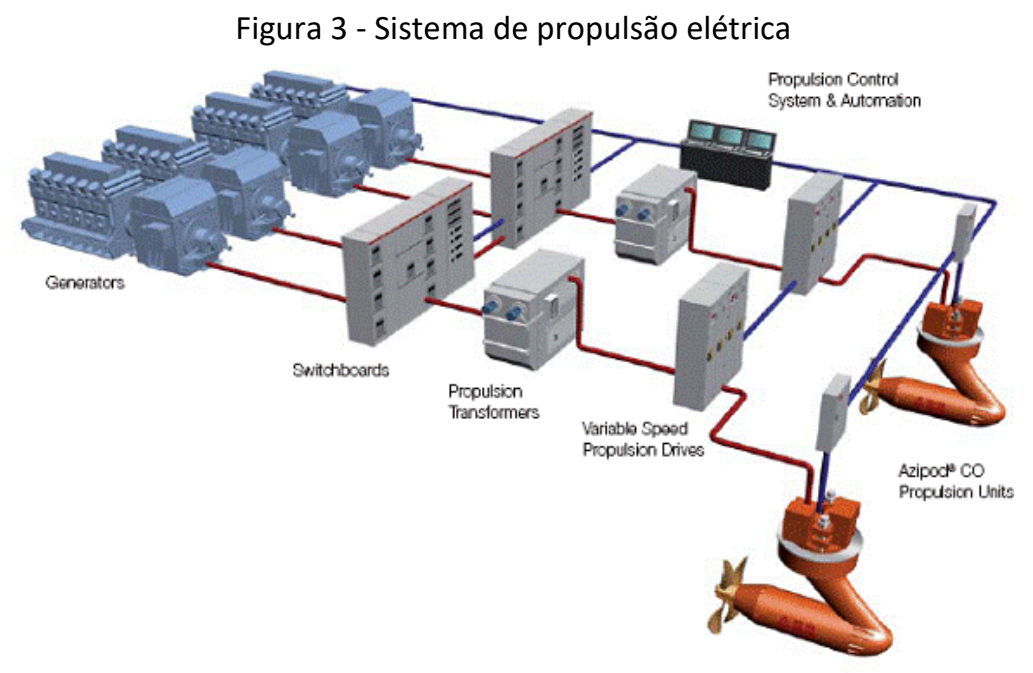

Fonte: (deno.oceanica.ufrj.br, acessado em 08/05/2018)

Figura 4 - Esquema de propulsão diesel-elétrica

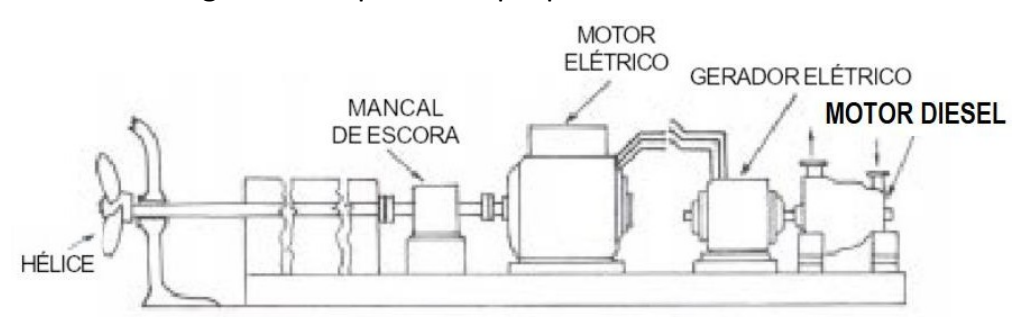

Fonte: (http://termo.furg.br/ArteNaval/Apres/ArtNav03b.pdf, acessado em 08/05/2018)

\subsubsection{Propulsão Mecânica X Propulsão Diesel-Elétrica}

Nos últimos anos, uma grande quantidade de pesquisas científicas vem sendo desenvolvidas em todo o mundo. Em destaque a tecnologia da Propulsão Elétrica Integrada (ALVES, 2007) que lança mão do acionamento elétrico e tem sido considerada pela Indústria Naval uma das tecnologias mais promissoras desse ramo (Figura 5).

Nas embarcações que possuem a propulsão mecânica convencional, a rotação do motor diesel dita a rotação do hélice. Existe uma grande desvantagem neste tipo de configuração, o motor não trabalha em seu rendimento ótimo. O que implica em um inevitável aumento do consumo de combustível de serviço e consequentemente, contribui para o aumento da emissão de gases poluentes. Em situações normais de operação a economia gira em torno de 15 a 25\% (BASSHAM, 2003) e tende a aumentar gradativamente em perfil de operação de posicionamento dinâmico, alcançando 40 a $50 \%$ de economia. Neste sistema propulsão o equipamento de acionamento principal pode ser uma turbina a vapor, motor diesel ou até mesmo uma turbina a vapor, que é 
conectada a linha de eixo propulsora com o intermédio das engrenagens redutoras. Esse arranjo ocupa mais espaço nas praças de máquinas e eleva o custo de manutenção em relação a propulsão elétrica integrada. Um ponto de destaque é que navios que usam essa configuração necessitam de um diesel gerador auxiliar, usualmente localizado em um lugar diferente dos demais equipamentos, para fornecimento de energia elétrica para os sistemas auxiliares a bordo.

Dependendo do tipo de navio e do perfil operacional, algumas seleções da planta de propulsão são possíveis de serem implementadas. A confiabilidade, segurança da navegação, considerável redundância e o conforto da tripulação são exemplos de benefícios que se busca ao optar por essa forma de propulsão. A propulsão elétrica consiste na conversão de potência elétrica entre o equipamento de acionamento e os propulsores do navio (ALVES, 2007). Ou seja, a carga do navio que são os propulsores requerem alto torque e baixa rotação, já o motor elétrico fornece alta rotação e baixo torque, essa relação é gerenciada pela propulsão elétrica. Os chamados navios elétricos, futuramente abastecerão a frota de navios das maiores Marinhas do mundo.

Figura 5 - Propulsão diesel-elétrica

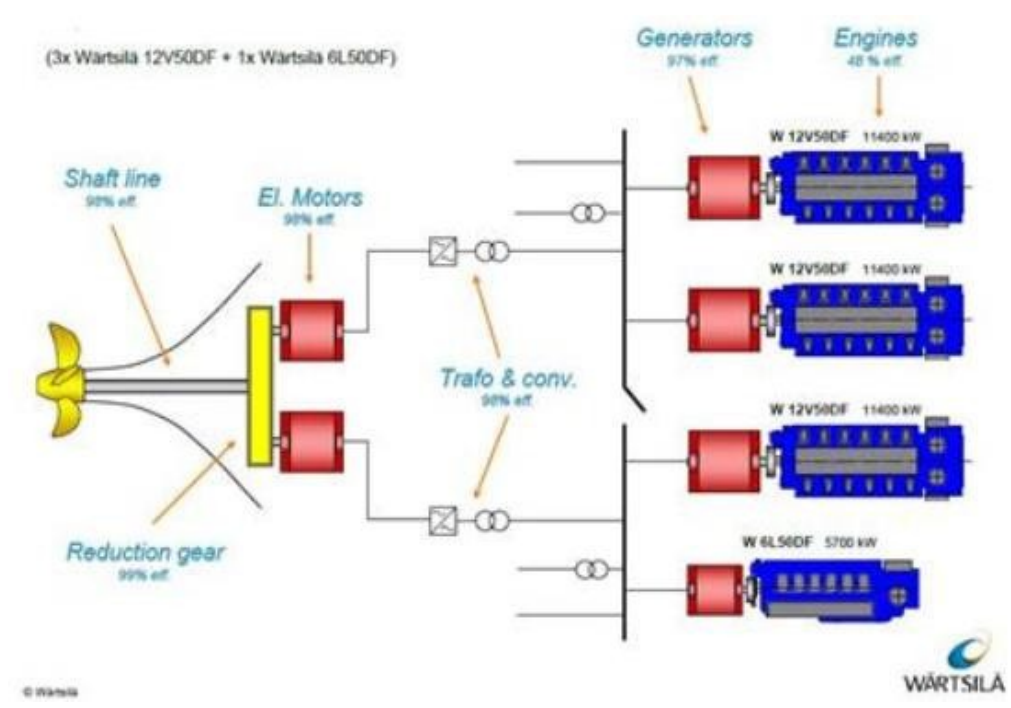

Fonte: (http://www.deno.oceanica.ufrj.br, acessado em 11/05/2018)

\subsubsection{Motores de Propulsão Elétrica}

A geração de energia elétrica de maneira universal e em maior quantidade se dá na forma de corrente alternada (C.A), entretanto para propulsão de navios, a geração de energia elétrica em corrente contínua (C.C) possui grande representatividade, sendo usada predominantemente na indústria militar em submarinos. Além disso, a energia de bordo pode ser gerada em corrente alternada e posteriormente retificada para corrente contínua. 
A máquina destinada à transformação de energia elétrica em mecânica é o motor elétrico, este desempenha papel fundamental na planta elétrica da embarcação, combinando fatores vantajosos como construção relativamente simples, custo de fabricação reduzido, baixo índice de manutenção, baixíssimo ruído em comparação com motores diesel e possui grande capacidade para adequar-se a mudanças bruscas de carga na hélice durante sua operação e navegação do navio, ou seja, variação brusca de velocidade da embarcação (LOURETO, 2016). A Figura 6 ilustra um motor elétrico que faz parte de um conjunto propulsivo do tipo POD.

Figura 6 - Motor Elétrico do tipo POD

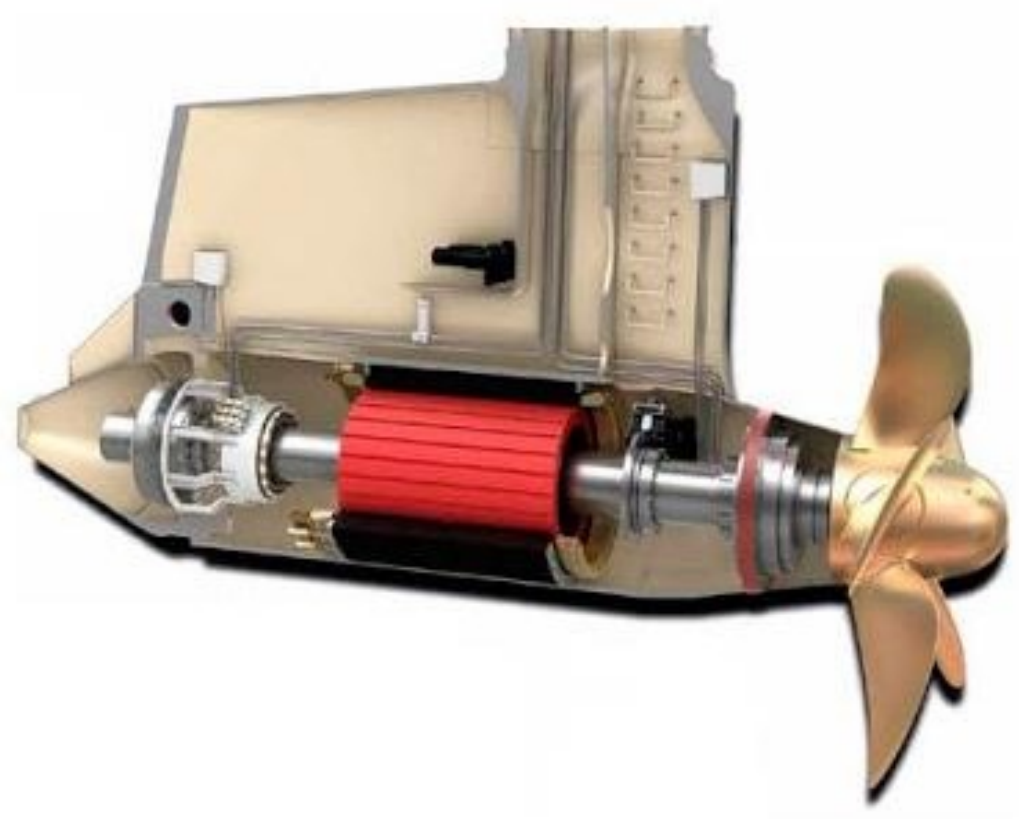

Fonte: (https://wilsonroque.blogspot.com.br/2017/06/um-comandante-e-seu-navio.html, acessado em 11/05/2018)

Na propulsão elétrica os motores têm a atribuição de fornecer potência mecânica a linha de eixo que se conecta a hélice, podendo ser chamada de máquina propulsora. Todo o estudo de eficiência energética e acionamento elétrico por conversores permeia em torno dessas máquinas girantes de grande potência. Quanto à alimentação de energia os motores podem ser classificados em motores de corrente contínua e de corrente alternada. Os de corrente contínua possuem comutadores e requerem alimentação em corrente alternada (ANGIOLLETI, 2016). Seu custo de manutenção é muito alto, mas a principal vantagem é a precisão no ajuste e controle flexível de velocidade de rotação. As máquinas de corrente alternada, são conhecidas comumente por alternadores. Sua utilização se dá em larga escala em navios, pois a distribuição de energia elétrica a bordo também é em corrente alternada o que otimiza os projetos.

A depender da natureza operacional e da aplicação os motores podem ser divididos em dois grupos: motores assíncronos e motores síncronos. O motor assíncrono atualmente é o mais utilizado na indústria para acionar máquinas de baixa potência, devido sua construção ser robusta

\begin{tabular}{l|l|l|l|l|l|r|r} 
Projectus | & Rio de Janeiro & V. 5 & N. 2 & P. $62-87$ & |
\end{tabular} 
e simples. A principal desvantagem é a sua velocidade que varia de maneira sutil com o aumento de carga aplicada (PEDROSA, 2016). Já o motor síncrono, opera com velocidade invariável e independente da carga mecânica na linha de eixo. Ou seja, a rotação do eixo é a mesma do campo girante. Possui alta eficiência em sistemas que demandam elevadas potências, como é o caso da propulsão dos navios, por esse motivo vem sendo utilizado em diversos tipos de embarcações. Os motores de imã permanente possuem requisitos muito apreciados tais como: baixo peso e volume, pouca vibração e ruído, torque suavizado e grande rendimento (PEDROSA, 2016).

\subsubsection{A Descoberta dos Supercondutores}

Por volta de 1911, o cientista holandês Heike Kamerling-Onnes (1853-1926), comprovou através de seus estudos que o mercúrio tinha a sua resistividade elétrica reduzida lentamente com a temperatura e em torno de 4,2 $\mathrm{K}$ ela rapidamente desaparecia. Isso intrigou a comunidade científica e foi a primeira observação de um material com resistência elétrica nula. Onnes chamou esse fenômeno de supercondutividade e a temperatura no qual este fenômeno ocorre chamou-se de temperatura crítica (Tc) (OSTERMANN, FERREIRA e CAVALCANTI, 1998).

Até 1986, os melhores supercondutores apresentavam temperatura crítica abaixo de $23 \mathrm{~K}$, ou seja, deveriam ser resfriados em hélio líquido para transformar-se em materiais supercondutores. Os supercondutores que apresentavam temperaturas críticas mais altas eram compostos à base de nióbio: $\mathrm{Nb}_{3} \mathrm{Ge}(23,0 \mathrm{~K}), \mathrm{Nb}_{3} \mathrm{Al}(18,9 \mathrm{~K}), \mathrm{Nb}_{3} \mathrm{Sn}(18,3 \mathrm{~K})$ e a solução sólida $\mathrm{Nb}-\mathrm{Ti}$ com 10,2 K. A temperatura crítica varia de material supercondutor para outro, para metais e ligas metálicas constatou-se que varia entre $1 \mathrm{~K}$ e aproximadamente $20 \mathrm{~K}$.

Em meados de 1986, em Zurique nos laboratórios da IBM, foram descobertos os chamados materiais cerâmicos supercondutores que possuíam temperaturas críticas muito elevadas. Nos últimos anos, provou-se que alguns óxidos cerâmicos complexos possuem temperaturas críticas acima de 100K. Na Figura 7 pode ser vista a estrutura cristalina de um dos materiais cerâmicos mais promissores e estudados atualmente, que é o $\mathrm{Y}_{1} \mathrm{Ba}_{2} \mathrm{Cu}_{3} \mathrm{O}_{7}-\mathrm{X}$ ou somente $\mathrm{YBCO}$, cuja temperatura crítica beira os 100K. Com este avanço, estas cerâmicas necessitam somente de nitrogênio líquido em torno de 77K para o seu resfriamento, não sendo mais necessário o emprego do hélio, que é muito mais caro visto pelo aspecto econômico (OSTERMANN, FERREIRA e CAVALCANTI, 1998). 
Figura 7 - Estrutura Básica da cerâmica supercondutora YBCO

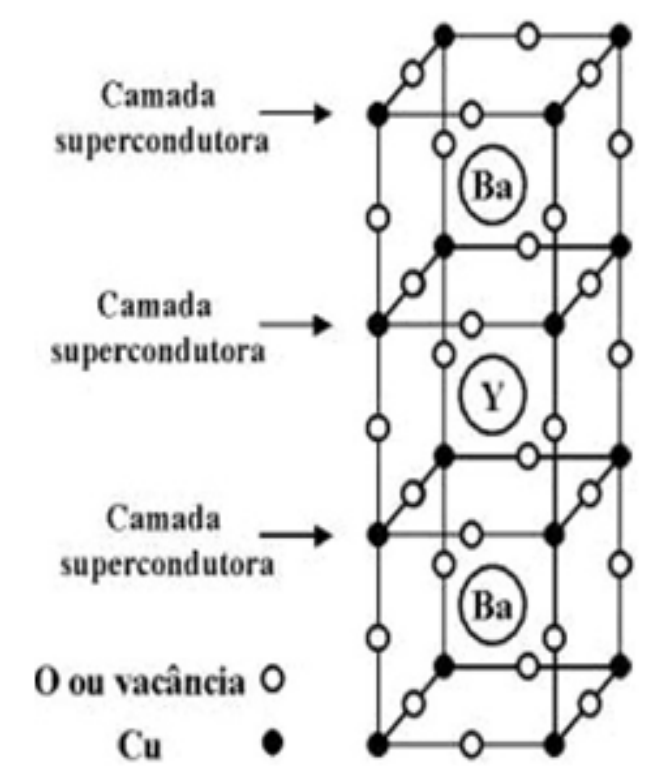

Fonte: (Adaptada do livro: "Superconductivity: its historical roots and development from Mercury to the ceramic oxides" de -(DAHL, 1992))

\subsubsection{Teoria da Supercondutividade}

O estado supercondutor origina-se da interação entre os pares de elétrons, os movimentos desses pares emparelhados ficam coordenados fazendo com que as dispersões por vibrações térmicas e por átomos de impureza sejam ineficientes. Por fim, a resistividade é nula, sendo proporcional à incidência de dispersão de elétrons. Hoje em dia diversas aplicações na área industrial e científica estão sendo estudadas, uma das principais aplicações são as bobinas supercondutoras para obtenção de grandes campos magnéticos. Nos supercondutores considerase a resistividade igual a zero, o que contribui diretamente para não existência de perdas por aquecimento, tornando os motores mais leves e compactos (SOLANO, 2007).

Os materiais supercondutores são classificados de duas maneiras, denominadas tipo I e tipo II. Os do tipo I, enquanto no seu estado supercondutor, são diamagnéticos; ou seja, todo o campo magnético aplicado será excluído do corpo do material, em um fenômeno conhecido como efeito Meissner. Conforme $\mathrm{H}$ aumenta, o material permanece diamagnético até o campo magnético ser atingido. Nesse ponto, a condução torna-se normal e ocorre a penetração completa do fluxo magnético. Diversos elementos metálicos, incluindo alumínio, chumbo, estanho e mercúrio, pertencem ao grupo dos supercondutores tipo I. Os supercondutores do tipo II, são completamente diamagnéticos quando o campo aplicado é pequeno e a exclusão do campo é total. Neste estudo bibliográfico o foco será os avanços tecnológicos aplicados a motores elétricos para esse tipo de supercondutor. Os supercondutores do tipo II são preferíveis na maioria das aplicações práticas, por 
dois motivos: suas temperaturas críticas e campo magnético crítico elevados. Atualmente, três supercondutores são mais utilizados: nióbio-zircônio ( $\mathrm{Nb}-\mathrm{Zr}$ ), ligas de nióbio-titânio ( $\mathrm{Nb}-\mathrm{Ti}$ ) e compostos de nióbio-estanho, $\mathrm{Nb}_{3} \mathrm{Sn}$.

Com a aplicação de um campo magnético relativamente grande, em temperaturas abaixo da temperatura crítica (Tc), o estado supercondutor deixa de existir. Isso porque o campo crítico (Hc) é uma função da temperatura e diminui com o aumento da temperatura. De modo análogo, para a densidade de corrente existe uma densidade de corrente aplicada crítica (Jc), abaixo do qual um material é supercondutor (CALLISTER e RETHWISCH, 2015). Os três parâmetros críticos estão ilustrados na Figura 8.

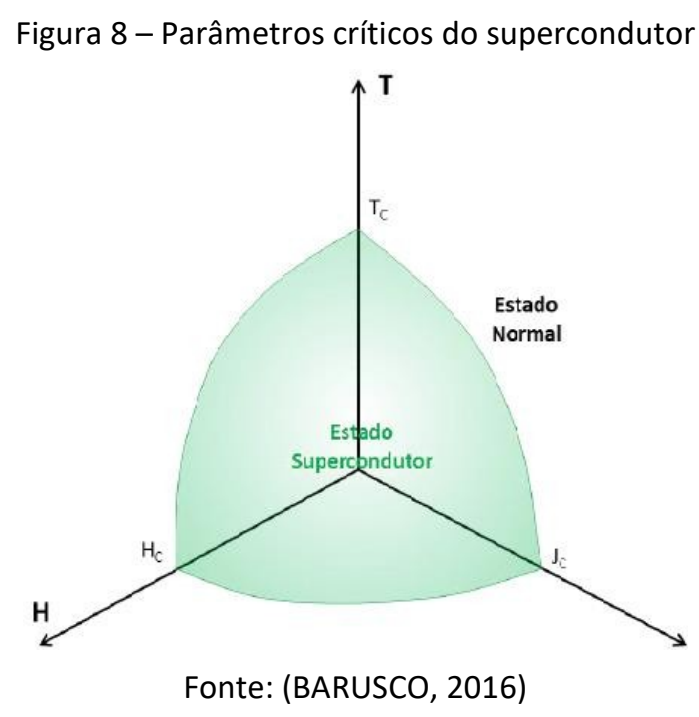

\section{DESENVOLVIMENTO}

\subsection{Motor Síncrono Rotativo Supercondutor (HTS)}

O uso de supercondutores aplicados a construção de máquinas elétricas é uma tecnologia nova e ainda menos madura que o motor de imã permanente, por exemplo. O motor HTS (Figura 9), usa um equipamento de resfriamento das bobinas supercondutoras alojadas no rotor denominado criostato. A função desse equipamento é arrefecer as bobinas a temperatura crítica do supercondutor abaixo de sua temperatura crítica, onde um material se torna supercondutor com resistência praticamente nula. As fitas supercondutoras presentes no rotor podem transportar uma grade quantidade de corrente com pouquíssima perda e atingir uma densidade de campo magnético maior que um motor síncrono convencional (PATEL, 2012). 


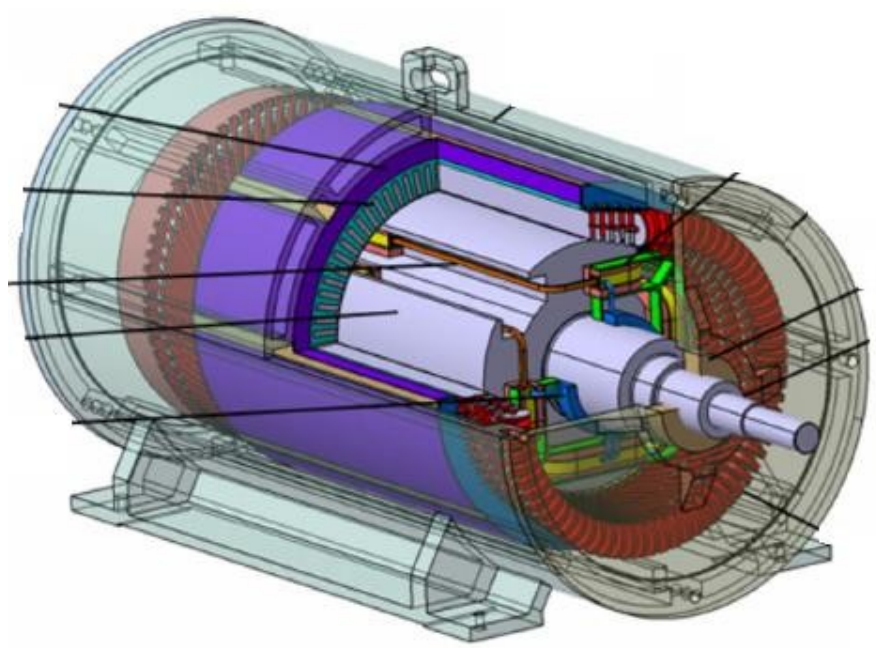

Fonte: (HARAN, 2017)

Segundo (GAMBLE, 2011), o motor síncrono supercondutor é constituído de um núcleo de ar com enrolamento do rotor composto por supercondutor de alta temperatura e o estator da máquina é construído sem dentes de ferro e resfriado por um fluido com características dielétricas. Como resultado dessa construção o motor supercondutor pode alcançar alto torque, grande densidade de potência, uma melhor eficiência energética e operar com menos ruído quando comparado às outras classes de motores existentes. Em termos de implementação dessa tecnologia, o sistema de arrefecimento criogênico representa grande parte do risco e do custo da operação do motor. A confiabilidade dele está atrelada diretamente à eficiência do sistema criogênico. Com o avanço dos estudos científicos para desenvolvimentos de novos compostos de altas temperaturas, que podem ser arrefecidos com nitrogênio líquido, este risco é reduzido. Antes necessitava-se que o arrefecimento fosse a base de hélio líquido, essa tecnologia foi abolida muito em função do alto custo atribuído ao hélio. (PATEL, 2012).

Com aplicação da tecnologia supercondutora o peso e volume são reduzidos em torno de um terço quando se trada de máquinas da classe de megawatt. Ao comparar a densidade de corrente de uma bobina supercondutora e uma bobina de cobre, a diferença é da ordem de 150 vezes em favor da bobina HTS e podendo chegar a uma impressionante eficiência de aproximadamente $98 \%$. Essas vantagens contribuem para a redução do consumo de combustível e peso da embarcação (SIEMENS AG, 2018). Os cientistas e engenheiros que pesquisam essa tecnologia tem muita preocupação com a degradação da fita supercondutora ao longo da vida útil do motor.Quando colocados na bancada de teste fica em operação por longas horas a fim de investigar e coletar dados operacionais. Essas são algumas das dificuldades que tornao desenvolvimento da aplicação dos supercondutores complexa (PATEL, 2012). 
2.2 Estudo Comparativo de um Motor Supercondutor para Propulsão Elétrica em Substituição a um MCP

O projeto consiste em um sistema de propulsão mecânica com motor de combustão principal ( $\mathrm{MCP}$ ) sendo responsável pelo acionamento do hélice através da linha de eixo. A proposta é avaliar quanto ao aspecto construtivo e curva de potência do motor e verificar a viabilidade de substituir o sistema de propulsão original por um sistema de propulsão elétrica com motor síncrono supercondutor de alta temperatura acionando o propulsor.

\subsubsection{Características da Embarcação}

As características principais do protótipo dessa embarcação classificada como uma lancha empregada para transporte de passageiros e carga gerais estão contidas na Tabela 1. A embarcação é dotada em seu projeto inicial de propulsão mecânica composta por um motor de combustão principal (MCP), linha de eixo e hélice de passo fixo. A maquete 3D do casco foi desenhada no software SolidWorks e pode ser observada na Figura 10.

\begin{tabular}{|c|c|}
\hline Caraterística & Medida \\
\hline Deslocamento & $42,00 \mathrm{t}$ \\
\hline $\begin{array}{c}\text { Comprimento } \\
\text { Total }\end{array}$ & $17,00 \mathrm{~m}$ \\
\hline Boca & $5,50 \mathrm{~m}$ \\
\hline Calado Carregado & $1,00 \mathrm{~m}$ \\
\hline
\end{tabular}

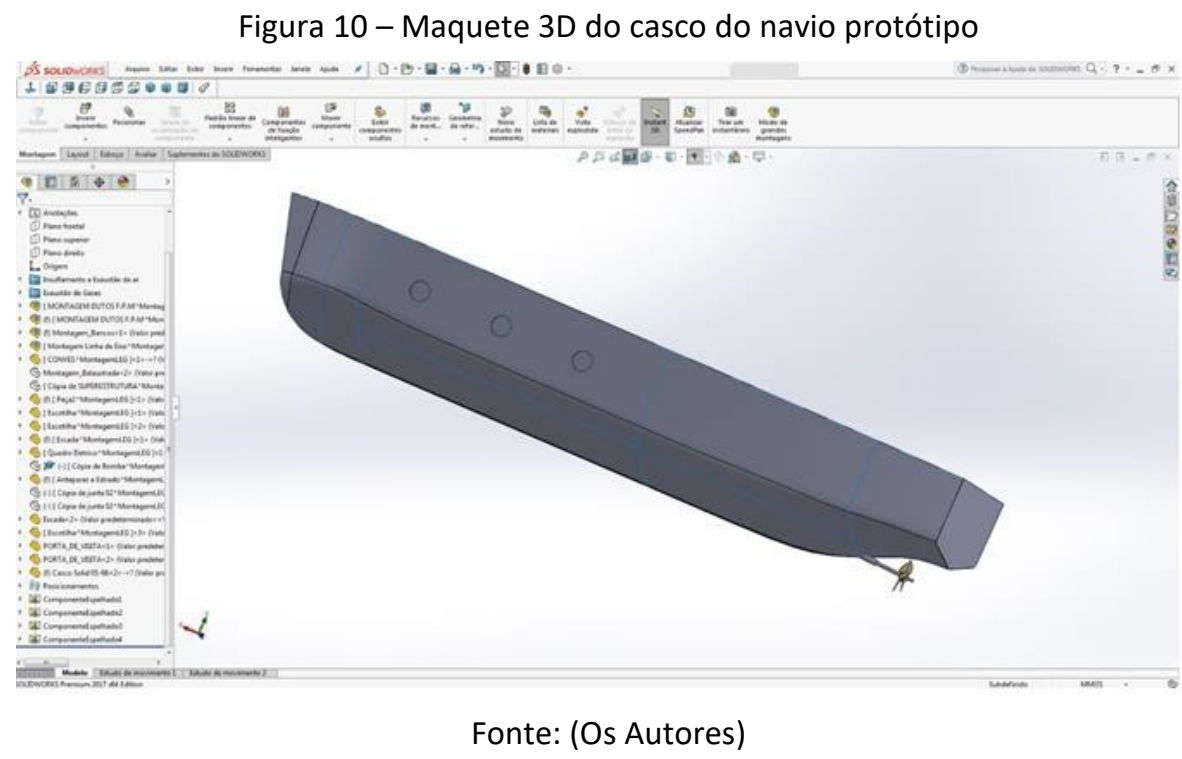




\subsubsection{Requisitos operativos e seleção de motor diesel da propulsão}

O navio é projetado para operar com um motor de combustão principal (MCP), com velocidade de cruzeiro de oito nós e para ter uma autonomia de oito horas com o limite de 36 travessias diárias. Em face ao casco modelado e apresentado na Figura 10, a potência mínima da propulsão requerida para movimentar o navio e atender a velocidade máxima mantida (VMM), é extraída da curva de potência do motor (Figura 11) dada pelo software NavCad 2014. Somando-se a esse dado, se faz necessário verificar a integração casco-hélice do navio para então determinar a potência do motor, ou seja, o programa através de seu método de cálculo verifica o melhor conjunto propulsor para o casco projetado e a potência requerida para o deslocamento do navio. Chega-se à conclusão que assumindo a velocidade máxima definida para a embarcação de 8 nós, de acordo com a Figura 12, a potência para o motor é de 79,1 kW.

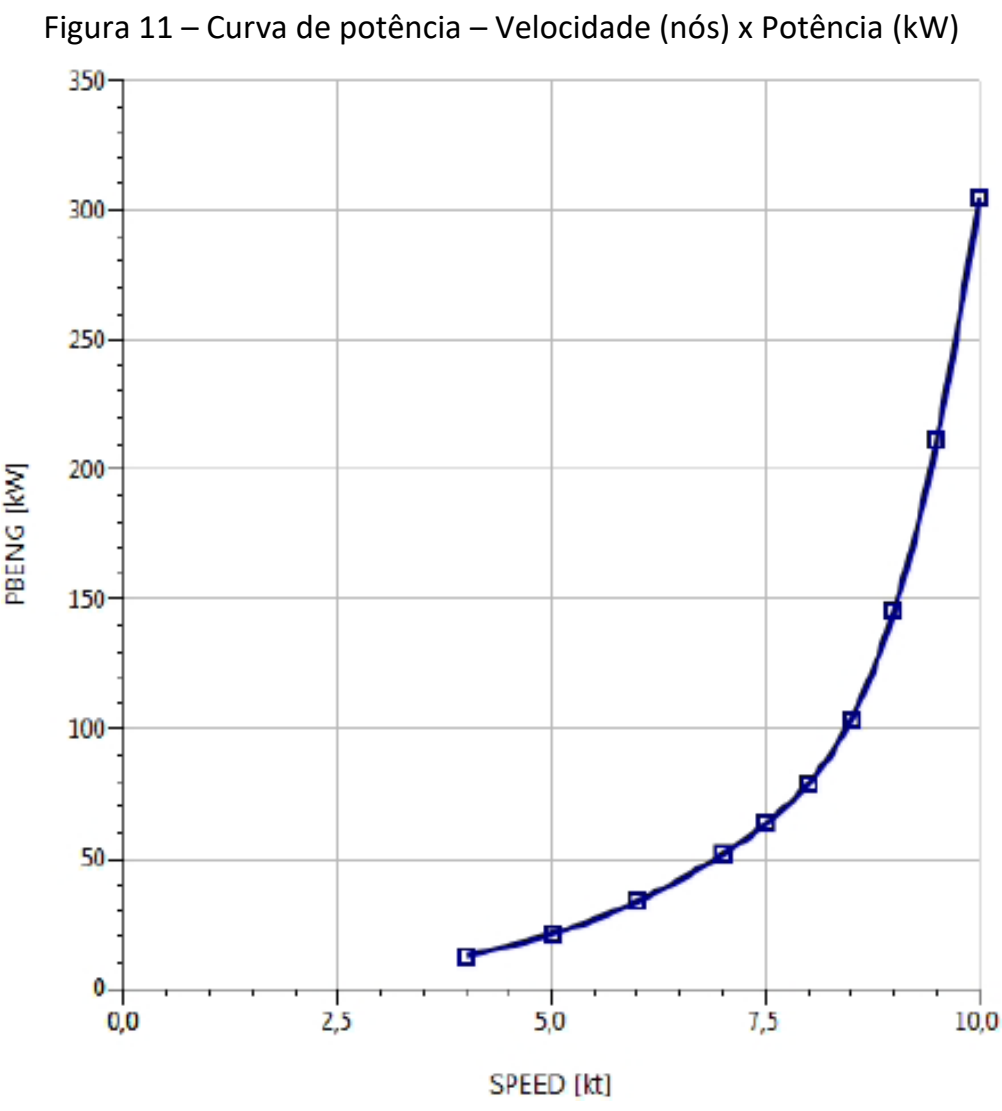

Fonte: (Navcad, 2014) 
Figura 12 - Dados de integração casco-hélice do motor

\begin{tabular}{|c|c|c|c|c|c|c|c|}
\hline & & \multicolumn{6}{|c|}{ POWER DELIVERY } \\
\hline $\begin{array}{l}\text { SPEED } \\
\text { [kt] }\end{array}$ & $\begin{array}{c}\text { RPMPROP } \\
\text { [RPM] }\end{array}$ & $\begin{array}{l}\text { QPROP } \\
{[\mathrm{kN} \cdot \mathrm{m}]}\end{array}$ & $\begin{array}{l}\text { QENG } \\
{[\mathrm{kN} \cdot \mathrm{m}]}\end{array}$ & $\begin{array}{c}\text { PDPROP } \\
{[\mathrm{kW}]}\end{array}$ & $\begin{array}{c}\text { PSPROP } \\
{[\mathrm{kW}]}\end{array}$ & $\begin{array}{c}\text { PSTOTAL } \\
{[\mathrm{kW}]}\end{array}$ & $\begin{array}{c}\text { PBTOTAL } \\
{[\mathrm{kW}]}\end{array}$ \\
\hline 4,00 & 368 & 0,31 & 0,14 & 11,9 & 12,3 & 12,3 & 12,7 \\
\hline 5,00 & 439 & 0,44 & 0,20 & 19,9 & 20,6 & 20,6 & 21,2 \\
\hline 6,00 & 515 & 0,59 & 0,27 & 31,8 & 32,8 & 32,8 & 33,8 \\
\hline 7,00 & 595 & 0,79 & 0,36 & 48,8 & 50,3 & 50,3 & 51,9 \\
\hline 7,50 & 637 & 0,90 & 0,41 & 59,8 & 61,7 & 61,7 & 63,6 \\
\hline$+8,00+$ & 684 & 1,04 & 0,47 & 74,4 & 76,7 & 76,7 & 79,1 \\
\hline 8,50 & 746 & 1,26 & 0,57 & 97,8 & 100,8 & 100,8 & 103,9 \\
\hline 9,00 & 829 & 1,59 & 0,72 & 137,0 & 141,2 & 141,2 & 145,6 \\
\hline 9,50 & 930 & 2,05 & 0,93 & 198,7 & 204,8 & 204,8 & 211,2 \\
\hline $10,00 !$ & 1043 & 2,64 & 1,20 & 286,5 & 295,4 & 295,4 & 304,5 \\
\hline
\end{tabular}

Fonte: (Navcad, 2014)

\subsubsection{Motor Diesel x Motor Síncrono Supercondutor}

A embarcação será dotada inicialmente de um motor de propulsão diesel com um eixo e propulsor. Posteriormente será comparada com o motor HTS de $100 \mathrm{Hp}$ para verificar a viabilidade da aplicação dessa tecnologia no protótipo da embarcação. O MCP selecionado para classe de potência requerida pela propulsão é o motor MWM, série 229, modelo TD229-6, de 97 kW de potência máxima nominal, com seis cilindros. Sendo necessária ao sistema uma engrenagem redutora, para controle da velocidade do propulsor. A Tabela 2 exibe um resumo das características técnicas do motor diesel selecionado.

\begin{tabular}{|c|c|}
\hline Fabricante & MWM \\
\hline Modelo & TD229-6 \\
\hline Série & 229 \\
\hline Potência (kW) & 97 \\
\hline Rotação (rpm) & 2500 \\
\hline Consumo (g/kW.h) & 228 \\
\hline Dimensões (LxHxW) (mm) & $1400 \times 835 \times 620$ \\
\hline Peso $(\mathrm{kg})$ & 600 \\
\hline
\end{tabular}

Por se tratar de uma embarcação relativamente simples, um tanque de combustível utilizado para serviço e armazenamento foi dimensionado. O combustível do tanque de armazenamento deverá ser aspirado pela bomba de óleo combustível do $\mathrm{MCP}$, o volume do tanque é calculado pela seguinte equação (1).

$$
V \min =\frac{\frac{\left(\sum P B \times b e\right)}{\rho} \times R}{v}
$$


A Tabela 3 mostra um comparativo do volume dos tanques de combustível para os dois sistemas. O volume mínimo do tanque de combustível é de 169,14 L, de acordo com o ENGENALMARINST $\mathrm{N}^{\circ}$ 05-03, Abreviaturas e Definições de Terminologia de Engenharia e Construção Naval, deve-se considerar um volume de combustível equivalente a $87 \%$ do volume moldado dos tanques de armazenamento de combustível. Assim, o volume moldado do tanque deverá possuir uma capacidade de armazenamento de, no mínimo, 194,42 litros.

No sistema de propulsão proposto em substituição ao diesel convencional, se faz necessário o uso de um grupo gerador para suprir a alimentação do motor HTS. O gerador selecionado possui potência de 120 kW, 230/380V e $60 \mathrm{~Hz}$. Considerando que o grupo gerador opera com $75 \%$ de carga, ele fornecerá a potência máxima de $90 \mathrm{~kW}$, suficiente para suprir o motor que demanda 74,4 kW. O volume do tanque de combustível do gerador deverá ser considerado para título de atendimento a autonomia da embarcação e cálculo do peso da embarcação, assim somados esses valores, será possível saber se o motor HTS atende aos requisitos de propulsão. O gerador, consome 25,3 I/h ou 6,7 gal/h de óleo combustível e o MCP 21,14 I/h. O volume do tanque necessário para atender as 8 horas diárias de operação é de 232,6 litros.

Tabela 3 - Comparativo do volume dos tanques de combustível e autonomia do navio

\begin{tabular}{|c|c|c|c|}
\hline Propulsão Mecânica & \multicolumn{4}{|c|}{ Propulsão Elétrica } \\
\hline Tempo de operação diária (h) & 9,182 & Tempo de operação diária (h) & 9,188 \\
\hline Consumo do MCP * & 21,143 I/h & Consumo do Gerador * & 25,3 l/h \\
\hline \hline Volume do Tanque de combustível (I) & $\mathbf{1 9 4 , 4 2}$ & Volume do Tanque de combustível (I) & $\mathbf{2 3 2 , 6}$ \\
\hline
\end{tabular}

O tanque de combustível para o grupo gerador sofreu um aumento de $16,41 \%$ no volume em comparação com o tanque de combustível para o motor a combustão principal. Em termos de volume deslocado do navio, observa-se um acréscimo de $32 \mathrm{~kg}$, o que não representa algo substancial e determinante para inviabilidade do sistema, quando comparado ao deslocamento do navio que totaliza 42t. Na Tabela 3 verifica-se que os requisitos de projeto são atendidos em ambos os sistemas de propulsão.

O motor aplicado no presente estudo comparativo é um motor síncrono HTS de $100 \mathrm{Hp}$ desenvolvido pela Korea Electrotechnology Research Institute in Korea (KERI) em estudo publicado em 2006. No software NavCad foi rodada uma nova simulação para o mesmo casco adotando um motor elétrico na propulsão, a curva de potência obtida como resultado pode ser vista na Figura 13. 
Figura 13 - Curva de potência considerando um motor elétrico na propulsão com tabela de potências

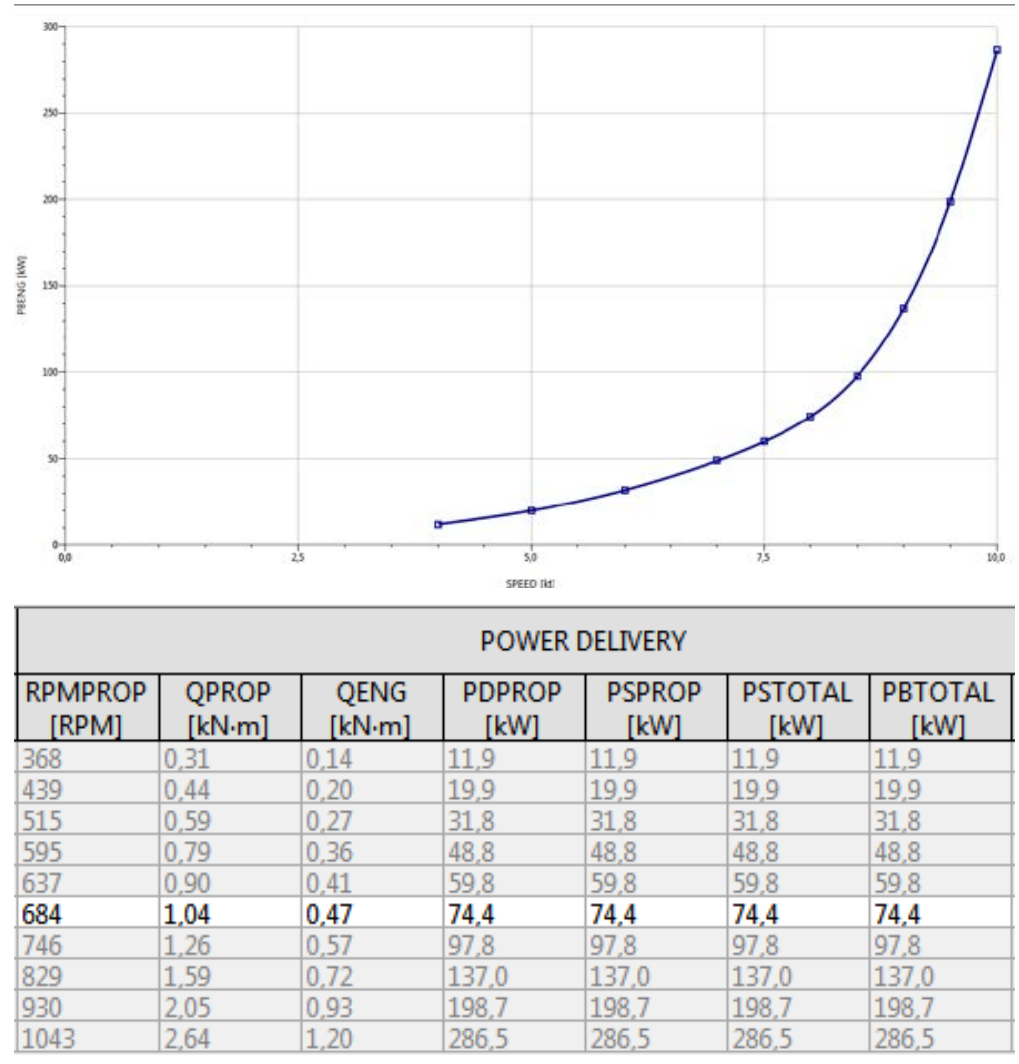

Fonte: (NavCad, 2014)

A nova potência requerida é de $74,4 \mathrm{~kW}$, portanto o motor HTS de $74,6 \mathrm{~kW}$ atende à demanda. É importante ressaltar que o modelo matemático do software, considera $10 \%$ de margem. As informações técnicas do motor constam na Tabela 4.

Tabela 4 - Informações técnicas do Motor HTS
\begin{tabular}{|c|c|}
\hline Potência (kW) & 74,6 \\
\hline Rotação (rpm) & 1800 \\
\hline Pólos & 4 \\
\hline Tensão $(\mathrm{V})$ & 380 \\
\hline Dimensões * - (CxL) $(\mathrm{mm})$ & $956 \times 478$ \\
\hline
\end{tabular}

Fonte: (KWON, 2005)

O motor HTS estudado trata-se de um protótipo, portanto um modelo não comercial. As dimensões são aproximadas conforme trabalho publicado por (KWON, 2005). O motor é comporto pelo rotor HTS e estator de núcleo de ar. Os enrolamentos de campo HTS são compostos por bobinas em dupla panqueca em pista enroladas com fita Bi-2223 da AMSC em aço inoxidável, mantados em suporte de compósito de fibra de vidro (KWON, 2005).

Para dar prosseguimento a investigação, é preciso verificar o peso dos equipamentos que compõe os dois sistemas. A Tabela 5 consolida os pesos dos respectivos equipamentos, o peso do motor HTS foi estimando em função do seu dimensional e segundo (KWON, 2005). O motor supercondutor alcança o resultado de $50 \%$ do peso de um motor síncrono convencional 
(SNITCHLER, 2005). É possível constatar que o peso total da propulsão diesel convencional somado ao tanque de combustível é de 1276 kg e da propulsão elétrica considerando o tanque do gerador é de $2596 \mathrm{~kg}$, o que representa um aumento de 103,4\%.

\begin{tabular}{|c|c|c|}
\hline Propulsão & Equipamento & Peso (kg) \\
\hline \multirow{4}{*}{$\begin{array}{c}\text { Diesel } \\
\text { Convencional }\end{array}$} & $\mathrm{MCP}$ & 600 \\
\hline & Redutora & 60 \\
\hline & $\begin{array}{l}\text { Painel elétrico (com banco de } \\
\text { baterias) }\end{array}$ & 450 \\
\hline & Tanque de combustível & 166 \\
\hline Total (kg) & & 1276 \\
\hline \multirow{6}{*}{ Elétrica } & Motor HTS & 300 \\
\hline & Painel Elétrico (sem banco de baterias) & 230 \\
\hline & Sistema de arrefecimento & 18 \\
\hline & Diesel Gerador & 1829 \\
\hline & Inversor & 20 \\
\hline & Tanque de combustível & 199 \\
\hline Total (kg) & & 2596 \\
\hline
\end{tabular}

\subsubsection{Requisitos de geração de energia e demanda do navio}

Os requisitos de geração de energia elétrica embarcada são necessários para atender a carga hotel do navio, ou seja, cargas de sistemas auxiliares, de navegação e instrumentos e iluminação a bordo. O projeto inicial (propulsão mecânica) prevê um circuito de baterias com retificadores CC/CA para alimentar as cargas de luzes de navegação, luzes internas dos compartimentos e do equipamento de comunicação interior. Quando atracado possui a capacidade de manutenção do banco de baterias através do retificador e carregador de $110 \mathrm{~V}$.

Para essa fase de projeto no cálculo da demanda de energia elétrica do navio, foram considerados dois critérios importantes: Margem de Crescimento de Projeto (MP) e Margem de Crescimento Futuro (MF), com valores de $10 \%$ e $15 \%$ da potência instalada, respectivamente. A MP tem como objetivo de prever um possível aumento das potências dos equipamentos durante a fase de projeto e construção do navio. Já a MF objetiva prever um provável aumento futuro na potência instalada e demanda de energia elétrica nas diferentes condições de operação durante a vida útil da embarcação, em função da instalação e modernização dos equipamentos a bordo por outros de potências maiores. A Tabela 6 mostra a contribuição dos sistemas para demanda de energia elétrica do navio. Tendo em vista que o gerador a $75 \%$ de sua carga fornece $90 \mathrm{~kW}$, o motor HTS consome $74,6 \mathrm{~kW}$, podemos concluir que o gerador possui a capacidade de suprir a demanda do navio, como pode ser visto na Tabela 7. 
Tabela 6 - Análise de demanda do navio protótipo

\begin{tabular}{|c|c|c|c|}
\hline \multicolumn{5}{|c|}{ Sistema } & \multicolumn{2}{|c|}{ Grupo I - Iluminação } \\
\hline Iluminação principal & 0,55 & 0,8 & 0,44 \\
\hline Luzes Externas & 0,6 & 1,0 & 0,6 \\
\hline TUG's & 5 & 0,3 & 1,5 \\
\hline Total & 6,15 & 2,54 \\
\hline Hodômetro & Grupo II - Navegação e Comunicação & 0,12 \\
\hline Luzes de Navegação & 0,12 & 1,0 & 0,42 \\
\hline Apito eletrônico & 0,53 & 0,8 & 0,2 \\
\hline VHF Porto & 0,2 & 1,0 & 0,06 \\
\hline Rádio Móvel & 0,06 & 1,0 & 0,1 \\
\hline Total & 0,1 & 1,0 & 0,9 \\
\hline Controle e Monitoração & 0,95 & & 0,2 \\
\hline Total & $\mathbf{G r u p o ~ I I I ~ - ~ I n s t r u m e n t a c ̧ a ̃ o ~}$ & 0,2 \\
\hline Total geral & 0,2 & 1,0 & 3,64 \\
\hline \hline
\end{tabular}

Tabela 7 - Tabela de cargas do navio considerando a propulsão elétrica

\begin{tabular}{|c|c|}
\hline Cargas do Navio & Potência $(\mathrm{kW})$ \\
\hline Serviço & 5,69 \\
\hline Motor HTS & $\mathbf{7 4 , 6}$ \\
\hline \hline Total & $\mathbf{8 0 , 3 0}$ \\
\hline
\end{tabular}

Fonte: (Os autores)

\subsubsection{Comparação entre o arranjo da propulsão diesel e propulsão elétrica com motor HTS}

O projeto básico do sistema propulsivo da embarcação de emprego geral, contempla um modelo diesel convencional com motor a combustão principal, redutora, linha de eixo e hélice. Esse arranjo ocupa um volume na praça de máquinas de $3,33 \mathrm{~m}^{3}$, este item tem como objetivo específico apresentar um breve estudo comparativo, que não possui um caráter conclusivo sobre o assunto, tendo em vista que seriam necessárias mais informações e estudo interdisciplinar com a Engenharia Naval, fugindo do foco deste trabalho. A Figura 14 e a Figura 15 referem-se as vistas superior do arranjo da praça de máquina com propulsão mecânica e vista lateral de boreste, ambos desenhos foram feitos no software AutoCad. 
Figura 14 - Vista Superior do arranjo da praça de máquinas

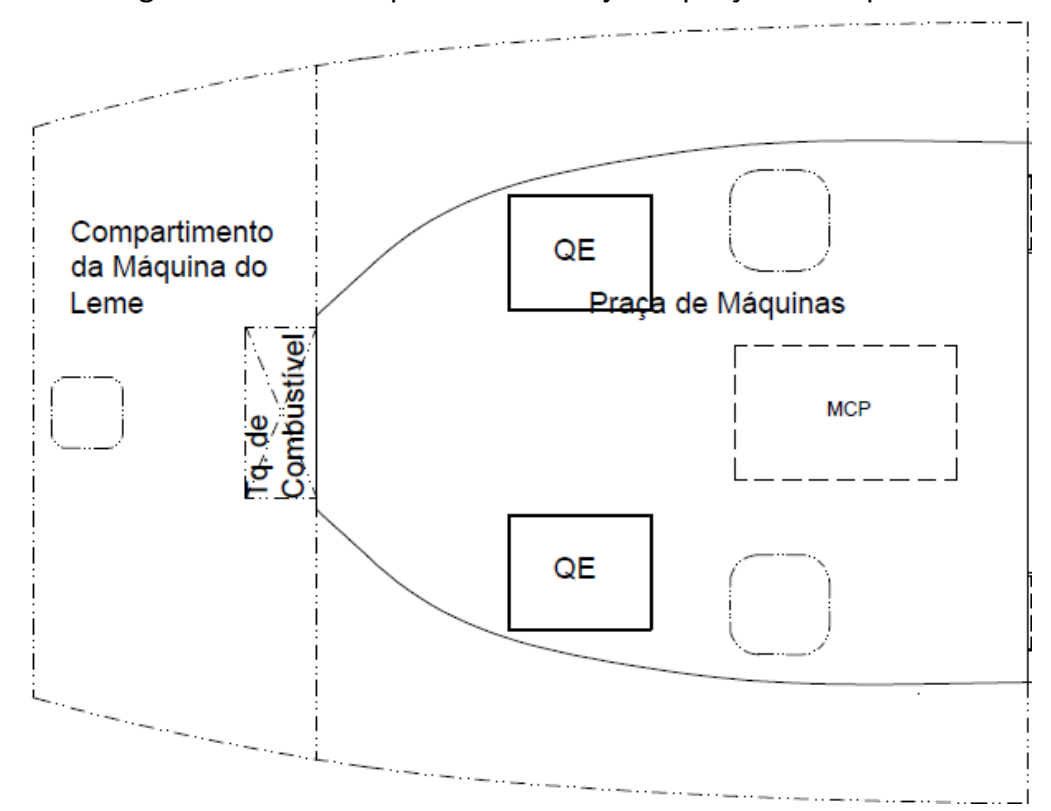

Fonte: (Os autores)

Figura 15 - Vista lateral de boreste praça de máquina do navio protótipo

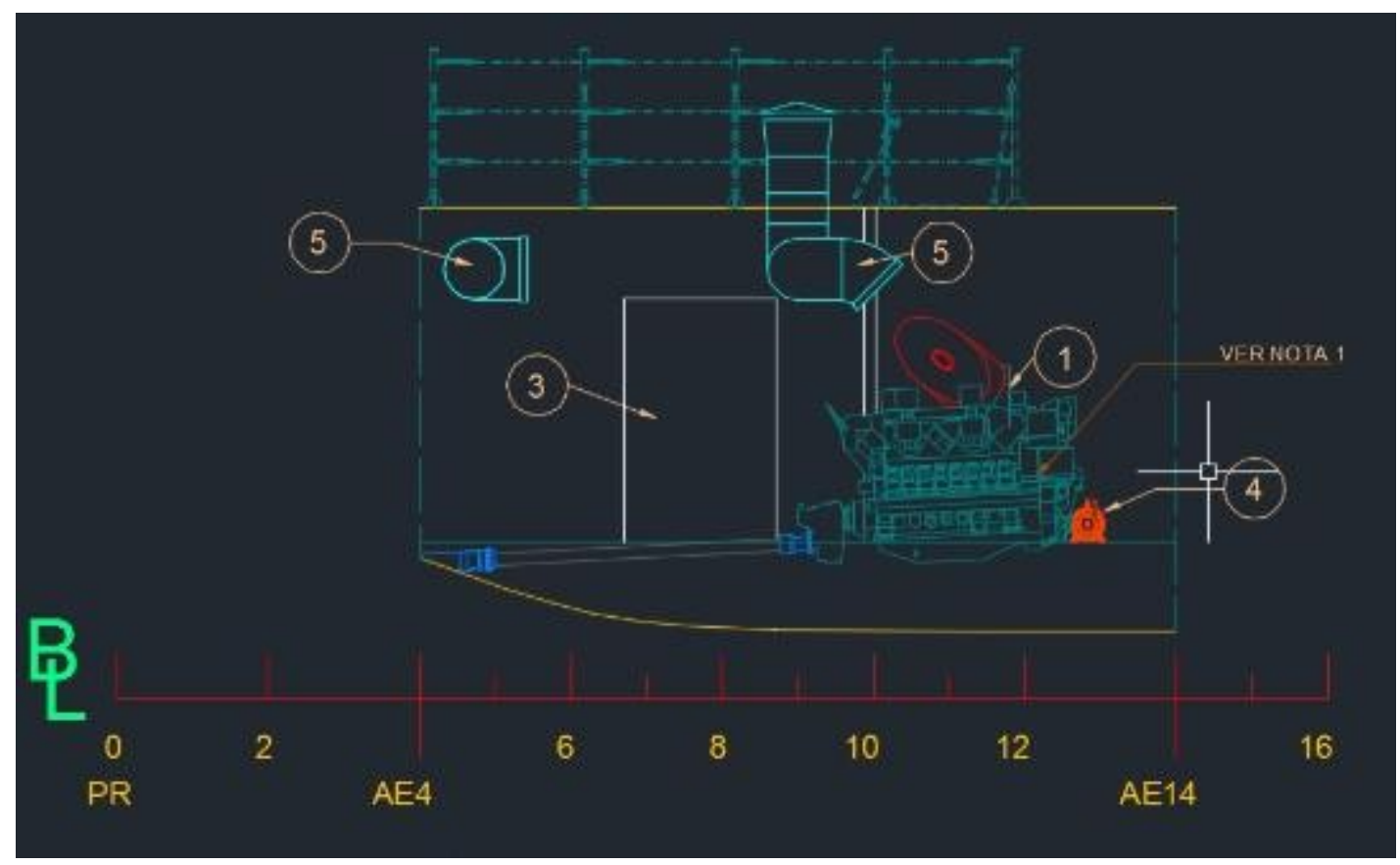

Fonte: (Os autores)

A Figura 15 nos dá uma dimensão da taxa de ocupação da praça, o MCP está representado pelo número 1, os painéis de BB e BE pelo número 3 e as tubulações de ventilação pelo número 5. A Figura 16 e a Figura 17 apresentam este mesmo arranjo em 3D desenhado no SolidWork, podendo ser vistos os mesmos equipamentos descritos anteriormente. 
Figura 16 - Arranjo 3D da praça de máquina - Propulsão Diesel mecânica

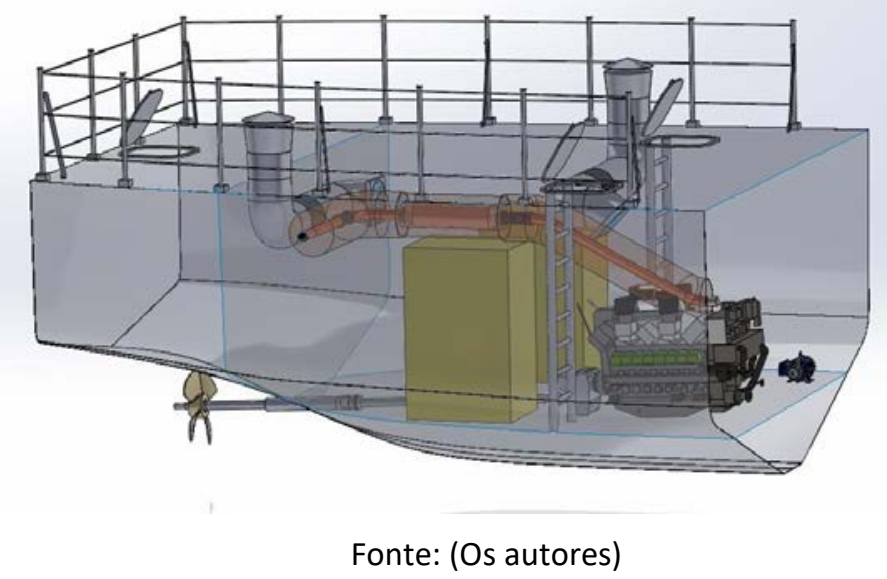

A seguir serão mostrados os arranjos com a praça de máquina com apropulsão elétrica, contemplando o motor HTS e sistema de arrefecimento. $\mathrm{O}$ volume ocupado pelos equipamentos que compõe a propulsão elétrica (motor HTS, painel elétrico força, inversor de frequência, criostato e gerador) é de 4,18 $\mathrm{m}^{3}$, o arranjo é apresentado na Figura 17.

Figura 17 - Vista da praça de máquinas pela popa

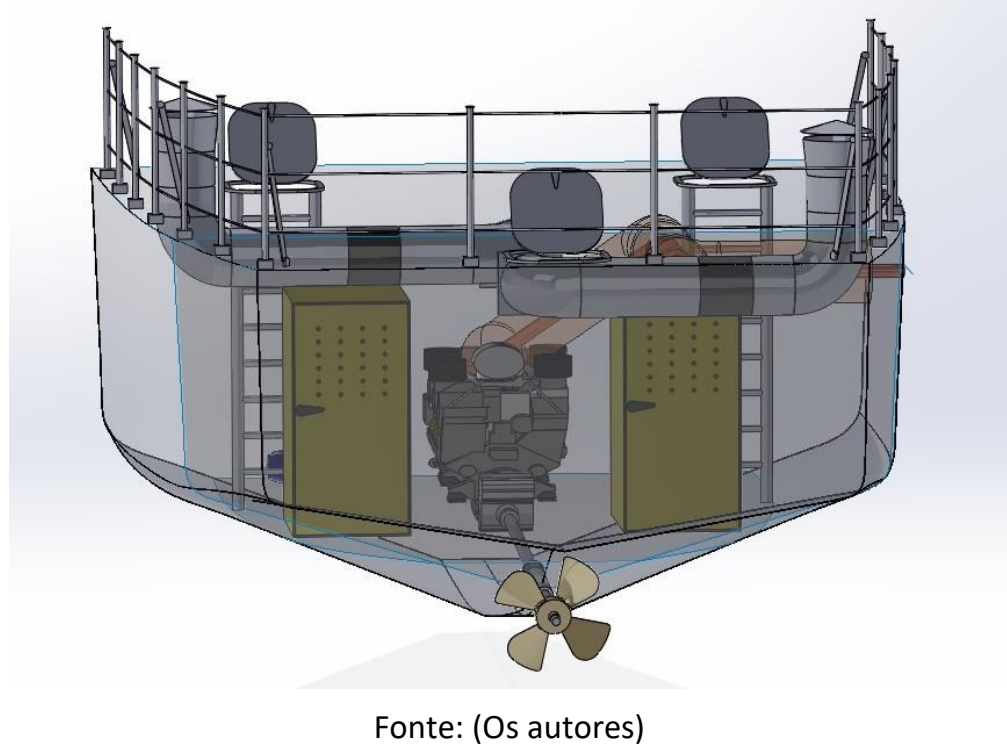

Através da Tabela 8 vê-se que o volume total ocupado pelos equipamentos da propulsão diesel é de 3,33 $\mathrm{m}^{3}$ e da propulsão elétrica é de 4,18 $\mathrm{m}^{3}$. Com isso podemos concluir que com as modificações propostas o espaço físico foi elevado em $25,5 \%$ no interior da praça de máquinas. A redução do painel elétrico contribui para uma maior facilidade de dispor os equipamentos, no entanto o gerador é o maior equipamento da praça, contrabalanceando e pesando de forma negativa pois a única forma de dispor dele na praça é conforme mostrado na Figura 17. Por fim, só o volume não é o suficiente, pois outros critérios e arquitetura naval devem ser observados, mas 
esse dado fornece uma boa ideia sobre a diminuição de espaço alcançada com a propulsão elétrica com uso de motor síncrono HTS.

Tabela 8 - Comparação do volume ocupado nas praças de máquinas

\begin{tabular}{|c|c|}
\hline Propulsão Diesel Convencional \\
\hline Equipamento & Volume $\left(\mathrm{m}^{3}\right)$ \\
\hline MCP & 0,716 \\
\hline Redutora* & 0,052 \\
\hline Painéis Elétricos & 2,56 \\
\hline Total & $\mathbf{3 , 3 3}$ \\
\hline
\end{tabular}

\begin{tabular}{|c|c|} 
Propulsão Elétrica com motor \\
HTS \\
\hline Equipamento & Volume $\left(\mathrm{m}^{3}\right)$ \\
\hline Motor HTS & 0,218 \\
\hline Criostato & 0,032 \\
\hline Painel Elétrico & 1,28 \\
\hline Painel do Inversor & 0,09 \\
\hline Gerador & 2,56 \\
\hline \hline Total & $\mathbf{4 , 1 8}$ \\
\hline
\end{tabular}

Fonte: (Os autores)

Com relação ao aspecto da manutenção dos equipamentos, essa modificação no tipo de propulsão reduz os custos de manutenção devido a retirada da redutora, linha de eixo e motor a combustão. Somando-se a isso, a discussão sobre a questão ambiental é latente, a planta elétrica é mais eficiente e reduz as emissões de poluentes (devido a retirada do MCP e rede de descarga de gases), redução de ruído e temperatura da praça de máquinas, melhorando as condições de trabalho no interior dela. Face a planta elétrica da embarcação, com o advento da propulsão elétrica o banco de baterias e retificadores são retirados, o grupo gerador fica encarregado de suprir a demanda total do navio, carga hotel e propulsão. A qualidade da energia também melhora com as saídas dos carregadores de baterias. Na Figura 18 pode ser vista a praça de máquina, destaca-se o motor HTS ocupa um espaço físico muito menor que o $\mathrm{MCP}$, porém, o grupo gerador é o equipamento que ocupa mais espaço na praça. O painel elétrico foi reduzido, inicialmente eram dois painéis elétricos e na nova concepção apenas um.

Figura 18 - Arranho 3D da propulsão elétrica com motor HTS

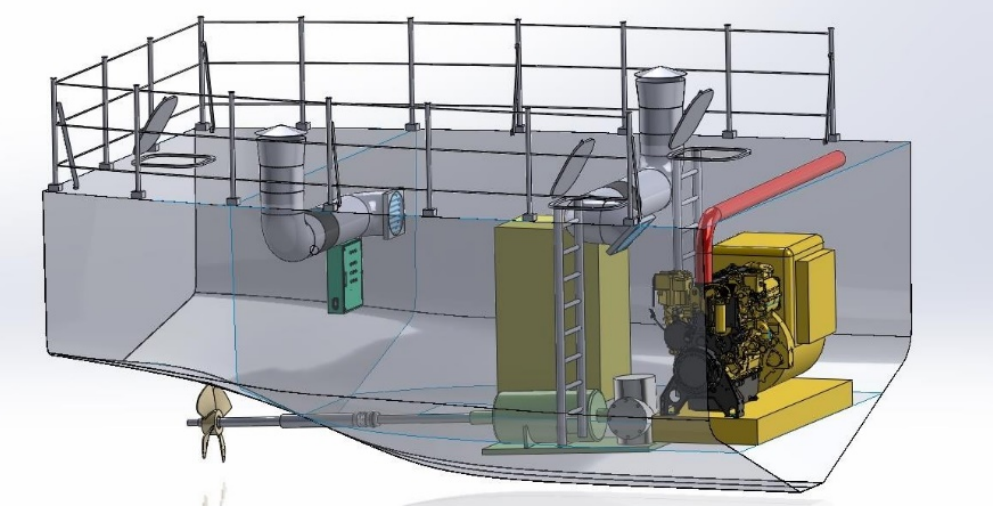

(Fonte: Os autores) 


\subsubsection{Custo Estimado da propulsão elétrica com motor síncrono HTS para o navio protótipo}

Aqui, objetivamos estabelecer uma estimativa do custo dos dois sistemas de propulsão, verificando qual se torna mais viável para a aplicação que está sendo estudada. Deve-se destacar que se trata de uma pesquisa inicial, que não leva em consideração todos os aspectos, servindo apenas para dar um direcionamento e uma noção mais precisa da ordem de grandeza envolvida no custo de aquisição da propulsão elétrica com motor síncrono HTS. Segundo (JANG, 2003), motores síncronos supercondutores sem núcleo de ferro e com rotor supercondutor podem reduzir o tamanho e as perdas com relação aos motores convencionais, sendo mais competitivos. Os motores HTS são mais eficientes do que os motores LTS, devido a temperatura operacional ser mais alta. $\mathrm{O}$ arrefecimento criogênico neste projeto fica a cargo do nitrogênio líquido a $30 \mathrm{~K}$.

Mas, para isso, tem-se um custo alto com a produção das bobinas supercondutoras, para (BAIK, 2005) a principal preocupação em projetos de máquinas supercondutoras reside na redução do custo das fitas Bi-2223 HTS, insumo utilizado no enrolamento das bobinas que transportam corrente a $30 \mathrm{~K}\left(-243^{\circ} \mathrm{C}\right)$. O preço do metro do fio supercondutor é de aproximadamente US $\$ 35,00$. O custo da bobina HTS da máquina compõe a grande fatia do custo total. Segundo (JANG, 2003), cada conjunto da bobina de campo é composta por 5 panquecas duplas em pista de corrida, sendo necessários 1150 metros de fio supercondutor HTS. Portanto o custo da bobina do rotor é de US\$ $40.250,00$.

A Tabela 9 mostra um quadro comparativo das estimativas de custo do sistema de propulsão diesel convencional e da propulsão elétrica com motor síncrono supercondutor. Para efeito de estimativa inicial de custo foram levadas em consideração publicações científicas, bem como propostas de fornecedores ofertadas em projetos anteriores a este. Por fim o custo total dos

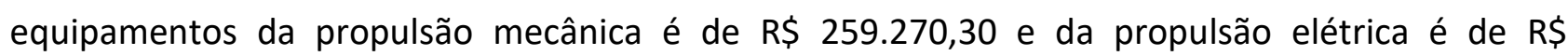
789.014,00, considerando o dólar comercial a $\mathrm{R} \$ 3,91$. Com isso, é possível atestar que o sistema proposto, considerando somente o valor estimado dos equipamentos da propulsão, é 304,32 \% mais caro que o mecânico. Este custo elevado pode ser explicado pelo valor do fio supercondutor e do equipamento auxiliar do motor de resfriamento criogênico. Como trata-se de uma embarcação de pequeno porte esse aumento no custo da propulsão, não se levando em consideração os sistemas auxiliares, é muito significativo do ponto de vista de custo de projeto. 
Tabela 9 - Estimativa de custo dos sistemas propulsivos

\begin{tabular}{|c|c|}
\hline \multicolumn{2}{|c|}{ Propulsão Diesel Convencional } \\
\hline Equipamento & Custo (R\$) \\
\hline MCP & $82.320,00$ \\
\hline Redutora e Linha de Eixo & $58.560,00$ \\
\hline Painéis Elétricos & $118.390,30$ \\
\hline \hline Total & $\mathbf{2 5 9 . 2 7 0 , 3 0}$ \\
\hline
\end{tabular}

\begin{tabular}{|c|c|}
\hline \multicolumn{2}{|c|}{ Propulsão Elétrica com motor HTS } \\
\hline Equipamento & Custo (R\$) \\
\hline Motor HTS* & $188.853,00$ \\
\hline Criostato & $66.861,00$ \\
\hline Diesel Gerador & $508.300,00$ \\
\hline Painel elétrico e Inversor & $25.000,00$ \\
\hline \hline Total & $\mathbf{7 8 9 . 0 1 4 , 0 0}$ \\
\hline
\end{tabular}

*Considerando somente o custo da bobina de campo HTS

\subsubsection{Fabricação de modelo da propulsão elétrica com motor supercondutor}

O modelo foi concebido a partir da ideia de reproduzir a seção do casco que engloba praça de máquinas dos navios. As peças foram reduzidas em escala para que fosse possível a impressão 3D, devido a limitação de tamanho de peça que a impressora 3D pode confeccionar. A Figura 19 mostra a impressora 3D modelo Replicator do fabricante MakerBot utilizada no projeto, a mesma localizada no Espaço Maker do Centro Universitário Augusto Motta na unidade Bonsucesso. As peças impressas para montagem foram concebidas no SolidWork com intuito de verificar a possibilidade de montagem experimentalmente a fim de verificar possíveis interferências. A estrutura da praça de máquinas é composta pelo Diesel-Gerador, Motor HTS, Quadro Geral de Força e Quadro de comando, este último contemplando internamente o inversor do motor, conforme Figura 20. A Figura 21 ilustra o modelo da propulsão proposto contemplando todas as peças descritas anteriormente. Por questões econômicas o casco e as anteparas do modelo não foram impressas em 3D, optou-se pela fabricação em madeira e chapa de ferro.

Figura 19 - Impressora 3D MakerBot Replicator

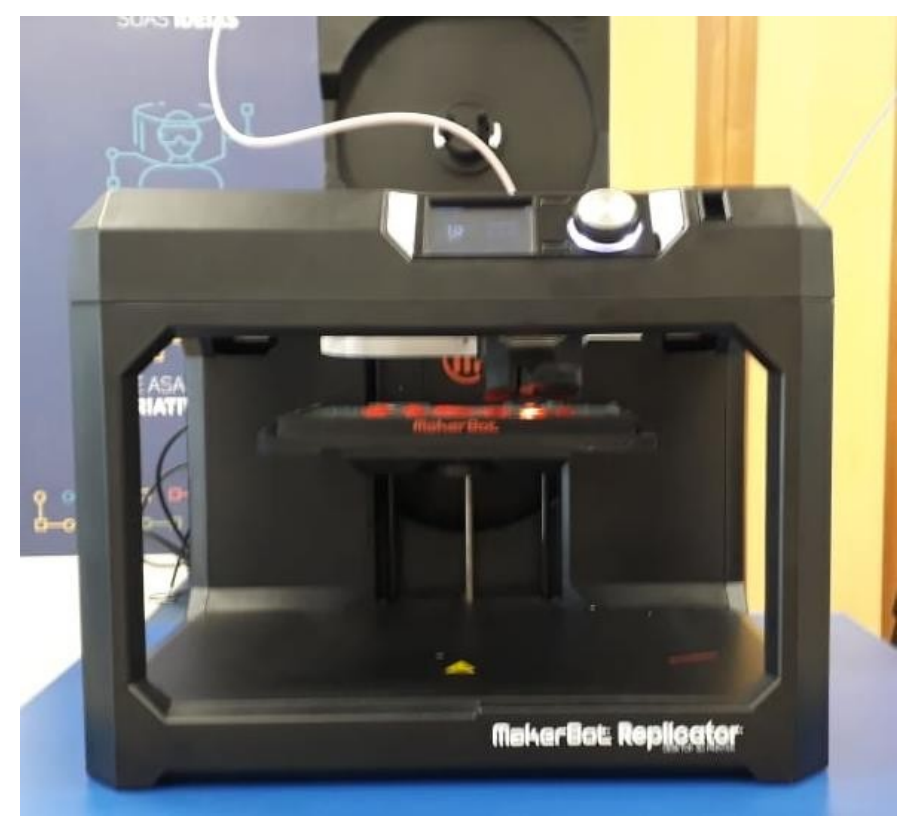

Fonte: (Os autores) 
Figura 20 - Peças modeladas pela impressora 3D

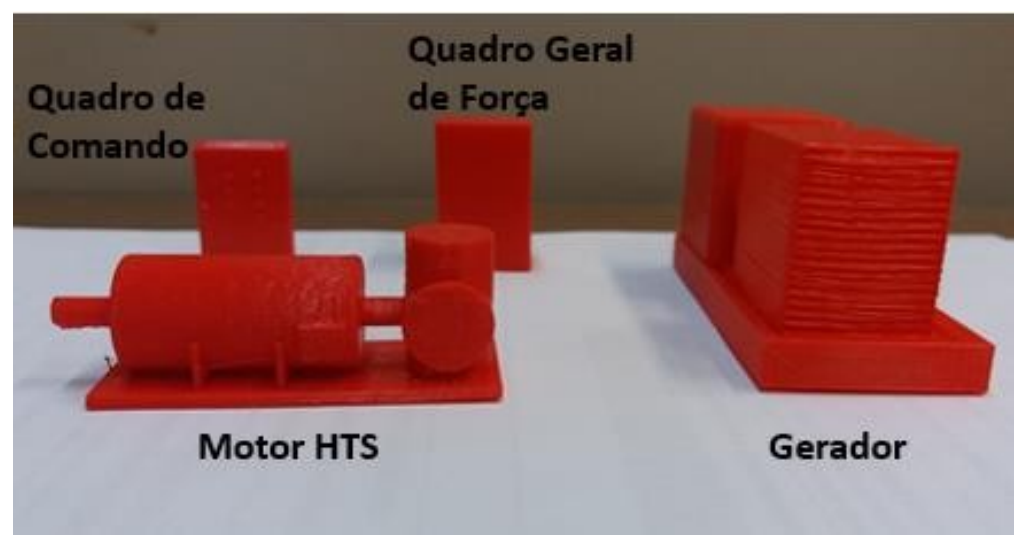

Fonte: (Os autores)

Figura 21 - Modelo da propulsão elétrica com motor supercondutor

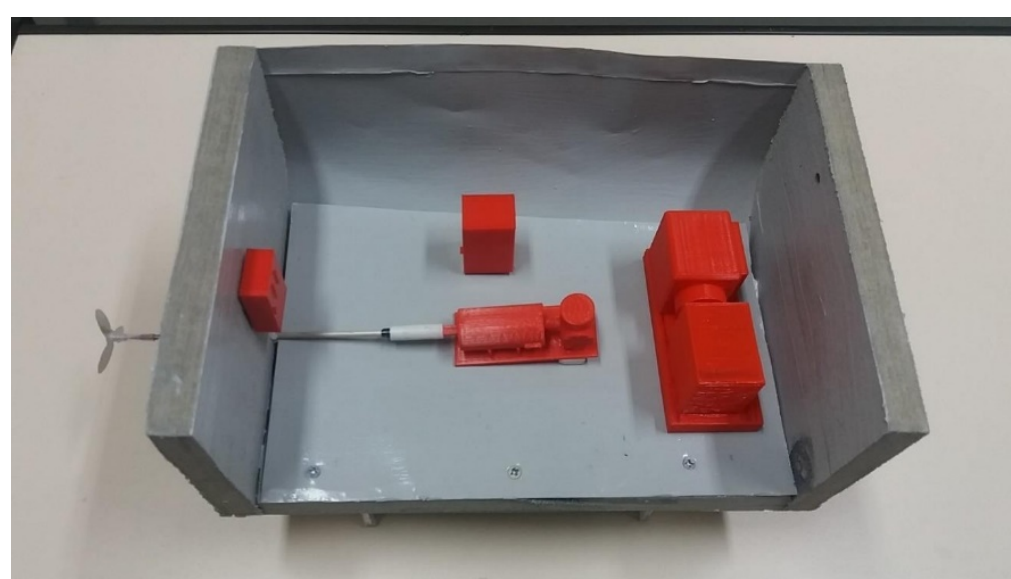

Fonte: (Os autores)

\section{CONSIDERAÇÕES FINAIS}

A pesquisa realizada foi de grande valia, pois com o advento da propulsão elétrica o banco de baterias e retificadores são retirados, o grupo gerador fica encarregado de suprir a demanda total do navio, carga hotel e propulsão. A qualidade da energia também melhora com as saídas dos carregadores de baterias. Na Figura 18 pode ser vista a praça de máquina, destaca-se o motor HTS que ocupa um espaço físico muito menor que o MCP, porém, o grupo gerador é o equipamento que ocupa mais espaço na praça. O painel elétrico foi reduzido, inicialmente eram dois painéis elétricos e na nova concepção apenas um. Outro aspecto a se destacar é que apesar do diesel gerador consumir mais combustível que o MCP, o tanque de combustível para abastecimento do gerador é $16,41 \%$ maior quando comparado com o tanque para motor diesel. A Tabela 5 permite concluir que a diferença de peso entre os dois tanques de abastecimento é de $33 \mathrm{~kg}$, observando que o peso deslocado do navio é de $42 \mathrm{t}$, esse aumento do peso do tanque é de baixa importância. 
O volume dos equipamentos da propulsão na praça de máquinas foi elevado em $25 \%$ em relação a configuração diesel convencional. Em relação ao peso geral, em resumo o peso total do sistema diesel convencional é de $1276 \mathrm{~kg}$ e da propulsão elétrica é de 2596 kg, representando significativa elevação de 49,15 \%. Vale destacar o aspecto econômico do projeto proposto, a realização do estudo permite uma conclusão mais efetiva sobre os custos de confecção do motor supercondutor. O principal parâmetro para dimensionamento do custo do sistema de propulsão elétrica foi o projeto do KERI - Korea Electrotechnology Research Institute, onde se apontou o valor aproximado de $\mathrm{R} \$ 188.853,00$ para projeto do rotor supercondutor. Este por sua vez, segundo (JANG, 2003) representa a maior fatia do custo total do motor HTS.

Nesse estudo foi possível obter um comparativo do custo global do sistema diesel mecânico

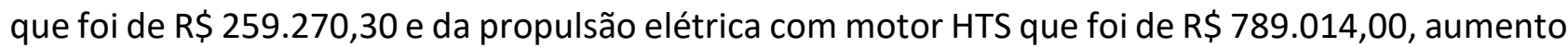
de $300 \%$ para a proposta apresentada. Através desse trabalho pode-se perceber que para uma embarcação de pequeno porte a substituição da propulsão torna-se onerosa. Portanto não atrativa para os construtores nos moldes propostos.

\section{REFERÊNCIAS}

ALVES. Propulsão Elétrica de Navios, Rio de Janeiro, Outubro 2007. 24-25.

ANGIOLLETI, M. A. Eletricidade Naval. [S.I.]: [s.n.], 2016. Disponivel em: <http://www.eletricidade.in/2-aulas_pdf/apostilas/eletricidade_naval.pdf>.

AZEVEDO, B. M. Propulsão Elétrica, Rio de Janeiro, 2015.

BAIK, S. K. Design Considerations for 1MW Class HTS Synchronous Motor. IEEE, Junho 2005.

BARUSCO, P. Caracterização de fitas supercondutoras $2 \mathrm{~g}$ na presença de campos magnéticos com diferentes ângulos de Incidência. UFRJ, Rio de Janeiro, Março 2016.

BASSHAM, B. A. An evaluation of electric motors for ship propulsion, Junho 2003.

CALLISTER, W. D.; RETHWISCH, D. G. Fundamentos da Ciência e Engenharia de Materiais. $4^{\circ}$. ed. [S.I.]: LTC, 2015.

CORDEIRO, A. Sistemas de Propulsão e Auxiliares, Santa Catarina, 2010.

DAHL, P. F. Superconductivity: Its Historical Roots and Development from Mercury to the Ceramic Oxides. [S.I.]: American Institute of Physics, 1992.

GAMBLE, B. Full Power Test of a 36.5 MW HTS Propulsion Motor. IEEE, Junho 2011. 
HARAN, K. High power density superconducting. IOP, 2017.

JANG, H.-M. Design and Electrical Characteristics Analysis of 100 HP HTS Synchronous Motor in 21st Century Frontier Project, Korea. IEEE, Junho 2003.

KWON, Y. K. Development of a $100 \mathrm{hp}$ Synchonous Motor With HTS Field Coils. IEEE, v. 15, Junho 2005. ISSN 2.

LOURETO, J. E. B. Propulsão Diesel Elétrica. Centro de Instrução Almirante Graça Aranha, 2016.

OSTERMANN, ; FERREIRA, L. M.; CAVALCANTI, C. J. H. Supercondutividade: uma proposta de inserção no ensino médio. 1. ed. Rio de janeiro: Instituto de Física, v. 8, 1998.

PATEL, M. R. Shipboard Propulsion, Power Electronics, and Ocean Energy. CRC Press, 2012.

PEDROSA, C. M. Propulsão Diesel Elétrica em Embarcações Offshore. Centro de Instrução Almirante Graça Aranha - CIAGA, Rio de Janeiro, 2016.

PINA, J. M. M. Desenho e Modelização de Sistemas de Energia Empregando Materiais Supercondutores de Alta Temperatura, Lisboa, 2010.

REIS, G. P. Propulsão Elétrica em Navios Mercantes. Centro de Instrução Almirante Graça Aranha, Rio de Janeiro, 2015.

SIEMENS AG. The guide of Marine frequency converters, Nurnberg, 2018.

SNITCHLER, G. The Performance of a 5 MW High Temperature Superconductor Ship Propulsion Motor. IEEE, v. 15, Junho 2005.

SOLANO, R. A. V. Estudo de Filmes Supercondutores para Aplicações em Dispositivos Eletrônicos. Universidade Estadual Paulista, São Paulo, Maio 2007.

TELLES, P. C. D. S. História da Construção Naval no Brasil. FEMAR, Rio de Janeiro, 2001. 